\title{
Kernos
}

Revue internationale et pluridisciplinaire de religion grecque antique

6 | 1993

Varia

\section{Figures grecques de l'intermédiaire, sous la direction de C. Calame, Études de lettres}

\section{Gérald Purnelle}

\section{OpenEdition}

\section{Journals}

Édition électronique

URL : http://journals.openedition.org/kernos/568

DOI : 10.4000/kernos.568

ISSN : 2034-7871

\section{Éditeur}

Centre international d'étude de la religion grecque antique

\section{Édition imprimée}

Date de publication : 1 janvier 1993

Pagination : 388-389

ISSN : 0776-3824

\section{Référence électronique}

Gérald Purnelle, «Figures grecques de l'intermédiaire, sous la direction de C. Calame, Études de lettres », Kernos [En ligne], 6 | 1993, mis en ligne le 07 avril 2011, consulté le 24 septembre 2020. URL http://journals.openedition.org/kernos/568 ; DOI : https://doi.org/10.4000/kernos.568 
délibéré pour inviter le lecteur à prendre connaissance de l'ensemble de la démarche ${ }^{17}$.

\section{Vinciane PIRENNE-DELFORGE (Liège)}

Figures grecques de l'intermédiaire, sous la direction de Claude CALAME, Études de Lettres, Université de Lausanne, 1992, 146 p.

Claude Calame a rassemblé, dans un numéro de la revue Études de Lettres, cinq articles aux thèmes très différents mais à la démarche comparable, et dont la plupart, nous prévient l'éditeur, sont issus de travaux de mémoires de licence.

Il s'agit, dans chaque étude, de dépasser le concept binaire du «même» et de l'«autre» pour démontrer, explicitement ou implicitement, que la pensée des Grecs ne fonctionnait pas selon un mode aussi simple, aussi tranché, et que le modèle structuraliste, trop réducteur, n'est pas toujours approprié pour en rendre compte : «si la pensée polaire souvent à l'œuvre en Grèce a pu faire croire que les oppositions mises à jour par l'analyse structurale traditionnelle bénéficiaient d'un fondement structurel, il est temps de constater que les Grecs se gardaient bien de penser le monde selon les canons de la logique binaire" (Cl. CALAME).

Partant, l'intérêt du recueil est double : dans la plupart des cas il offre, sur le sujet traité, de nouveaux éclairages; en outre, son apport sur le plan de la réflexion méthodologique est indéniable.

Dans un article intitulé Figures du tyran archaïque : entre le monstre et le sage, Christine YERLY analyse la représentation du tyran dans la poésie archaïque. Le tyran, tantôt monstreux, tantôt modèle de sagesse, est relégué aux marges de la société, de la normalité, mais son rôle d'arbitre et la transition qu'il assure entre pouvoir absolu et démocratie le réintègrent dans la cité.

Pierre VOELKE, dans Ambivalence, médiation, intégration : à propos de l'espace dans le drame satyrique, montre, par l'étude des données mêmes des textes conservés, que l'espace géographique où se déroule l'action des pièces n'est pas seulement l'emblème du monde sauvage opposé au monde civilisé, mais qu'il représente un lieu de passage de l'un à l'autre.

17 Quelques erreurs et coquilles au passage : p. 16 : dans lesquelles et non dans laquelle; p. $37, \S 3.3$. : mise au jour et non mise à jour; p. $42,2 \mathrm{e} \S:$ mettre au jour et non mettre à jour; p. 103, § 5.3. : pouvoir et non pouvir; p. 144, $\$ 1.2 .1$. : on va parler et non on vas parler; p. 152, $\S 1.4 .2$. : Souda et non Suda; p. 322, 1er $\S$ : civilisatrice et non cvilisatrice; p. 388, n. 85 : Pithoïgia et non Phitoïgia. 
Claude CALAME signe également une étude : Espaces liminaux et voix discursives dans l'Idylle I de Théocrite : une civilisation de poète. Il y revient sur l'un des poèmes les plus étudiés de Théocrite, en analysant la structure du texte, l'enchevètrement des différentes voix du poème (protagonistes, narrations, descriptions) et les espaces impliqués par chaque discours, l'œuvre se ramenant à une fiction poétique qui «insère en milieu urbain le domaine intermédiaire des pasteurs musiciens».

Pour Anne Julia VOILLAT SAUER (Entre exotisme et héroïsme : les Celtes de Posidonios), l'ethnographe stoïcien, en décrivant minutieusement les mœurs des Celtes de Gaule, ne les situe pas radicalement dans la barbarité (malgré plusieurs coutumes inacceptables pour un Grec); certains aspects de leur mode de vie sont assimilés à des mours typiquement grecques (celles des héros homériques); d'autre part, la sujétion des Celtes à leurs sages est propre à intéresser un stoïcien, pour qui l'humanité est unique et fondée sur la possession du logos.

Enfin, en synthétisant les références aux poèmes homériques apparaissant dans l'Histoire vraie de Lucien, Danielle VAN MALMAEDER tend à montrer que le théoricien de l'historiographie s'attaque uniquement, par son pastiche, aux récits imaginaires produits par ces contemporains; l'œuvre d'Homère n'est pas strictement assimilable aux ouvres de fiction que Lucien critique : elle reste pour lui le modèle idéal qu'il lui plaît d'imiter lorsqu'il se livre lui-même à la fantaisie.

Gérald PURNELLE (Liège)

\section{J. LECLANT, G. CLERC, Inventaire bibliographique des Isiaca (IBIS). Répertoire analytique des travaux relatifs à la diffusion des cultes isiaques 1940-1969, R-Z, Leyde, New York, Copenhague, Cologne, E.J. Brill, 1991, 1 vol. in- $8^{\circ}$, IX +374 p. (Études préliminaires aux religions orientales dans l'Empire romain, 18).}

En 1971, le professeur J. Leclant, avec la colaboration de Gisèle Clerc, mettait en route une bibliographie analytique de tous les ouvrages et articles relatifs aux isiaca et aux aegyptiaca parus entre 1940 et 1969. Cette vaste entreprise qui englobe tout l'espace méditerranéen, et souvent bien au-delà, s'est révélée tâche fort lourde, car les recherches en cette matière se sont fortement multipliées à partir de 1955. Aujourd'hui les auteurs nous présentent le quatrième et dernier volume de leur Répertoire, désormais riche de 1752 titres et de 405 pages d'index, une véritable somme bibliographique appelée à rendre les plus grands services à tous ceux qu'intéresse la diffusion des dieux et des objets égyptiens ou égyptisants dans le monde antique. 